\title{
Oocytes recovered from cows treated with retinol become unviable as blastocysts produced in vitro
}

\author{
C Hidalgo, C Díez ${ }^{1}$, P Duque ${ }^{1}$, J M Prendes², A Rodríguez¹ , F Goyache , I Fernández³ , \\ N Facal ${ }^{1}$, S Ikeda $^{1}, \mathrm{C}$ Alonso-Montes ${ }^{1}$ and E Gómez ${ }^{1}$ \\ Area de Selección y Reproducción Animal (SERIDA) and ${ }^{1}$ Area de Genética y Reproducción Animal (SERIDA), \\ Servicio Regional de Investigación y Desarrollo Agroalimentario (SERIDA), Camino de los Claveles, 604 - Somio, \\ Gijón 33203, Asturias, Spain, ${ }^{2}$ Cooperativa de Agricultores de Gijón, Carretera Carbonera s/n Gijón, Spain and \\ ${ }^{3}$ Consejería de Medio Rural y Pesca, Navia, Asturias, Spain
}

Correspondence should be addressed to E Gómez; Email: egomez@serida.org

P Duque is now at Centro de Fertilización in Vitro de Asturias (CEFIVA), Alvarez Garaya, 12 33206, Gijón (Spain)

\begin{abstract}
Retinoids have been shown to enhance developmental competence of the oocyte in cattle, sheep and pigs. In this study we investigated whether exogenous retinol stimulates the bovine oocyte during its intrafollicular growth and the time limits of exposure to exogenous retinol. In addition, we also determined the efficiency of ovum pick-up techniques in combination with retinol treatment and the viability of embryos after transfer to recipients. In Experiment 1, heifers were injected with retinol or vehicle, and concentrations of retinol in the blood were analysed on Day 0 (prior to injection), Day 1 and, together with follicular fluid, Day 4. Blood retinol increased by Day 1 and cleared on Day 4, but retinol remained higher within the follicle. In Experiment 2, oocyte donors were injected weekly with retinol or vehicle four times during a twice-per-week cycle of eight recovery sessions (starting 4 days before the first session), followed by a second eight-session cycle without treatment. Oocytes recovered were fertilized and cultured in vitro. Retinol treatment yielded higher numbers of low-quality oocytes throughout, although retinol measured during cycles did not change. Total oocytes, and morulae and blastocyst rates, increased during the first five sessions following treatment with retinol. As previously shown with oocytes from slaughterhouse ovaries, retinoic acid stimulated blastocyst development. Following transfer to recipients, blastocysts from oocytes exposed to retinol were unable to establish pregnancy. Our study confirms the existence of an effect of retinol on the intrafollicular oocyte in the cow and provides evidence regarding the teratogenic effect of retinol.

Reproduction (2005) 129 411-421
\end{abstract}

\section{Introduction}

Vitamin A (all-trans retinol; $\mathrm{ROH}$ ) and its metabolites are regulators of cell growth, embryonic morphogenesis and differentiation in many types of cell. These compounds, members of the retinoid family, play a fundamental role in controlling events during the cell cycle, affecting decisions to either continue proliferation or differentiate. In the cell there are several retinoid-binding proteins which play specific roles in regulating retinoid metabolism. While retinol-binding protein (RBP) is required for the intercellular transport of $\mathrm{ROH}$, cellular retinol-binding protein (CRBP) is responsible for transporting intracellular $\mathrm{ROH}$ that may be either stored or metabolized to retinoic acid (RA), the most important retinoid metabolite required for vertebrate embryogenesis (Morris-Kay \& Ward 1999). Bovine granulosa cells synthesize RBP and CRBP (Brown et al. 2003), and RBP mRNA has been detected in the oocyte (Mohan et al. 2001). Regulation of intracellular RA concentrations is to a great extent controlled by cellular RA-binding proteins (CRABPs). In the pig, detection of CRABP I is cycle stage-dependent, and luteal cells in dioestrus, together with oviduct and uterus in oestrus, contain the protein (Schweigert \& Siegling 2001). Rats have CRABP II in granulosa cells from mature follicles and luteal cells (Bucco et al. 1995, Wardlaw et al. 1997, Zheng et al. 1999).

In the live cell, biologically active retinoids mediate their effects by binding to two different kinds of nuclear receptors, namely, RA receptors (RARs) and retinoid $X$ receptors (RXRs), each having three subtypes, namely $\alpha$, $\beta$ and $\gamma$. Upon entering the nucleus all-trans RA and 9cis RA can activate RARs, whereas RXRs are activated only by 9-cis-RA (Mangelsdorf et al. 1994, Chambon 1996). Heterodimerization between RXR and RAR or other members of the steroid/thyroid hormone nuclear 
receptor superfamily (Chambon 1996), can occur in response to ligand-mediated activation. Heterodimers are capable of binding to specific DNA sequences named $\mathrm{RA}$ response elements, to increase or decrease the expression of a gene. Several component of the RA signalling pathway such as RAR $\alpha$ and $\gamma, \operatorname{RXR} \alpha$ and $\beta$, retinaldehyde dehydrogenase and peroxisome-proliferator activated receptor gamma, are expressed in bovine oocytes and embryos (Mohan et al. 2001, 2002) and in cumulus cells (Mohan et al. 2003). Immunostaining detected RAR $\alpha$, and RAR $\beta$ in blastocysts (Mohan et al. 2001, 2002) and RAR $\alpha$ and RXR $\beta$ in cumulus cells (Mohan et al. 2003).

It has been reported that the developmental competence of the oocyte is enhanced by $\mathrm{ROH}$ treatment in the cow (Shaw et al. 1995), sheep (Eberhardt et al. 1999) and gilt (Whaley et al. 1997, 2000), as well as in rabbits that have high blood levels of vitamin A (Besenfelder et al. 1996). In studies involving cows (Shaw et al. 1995), sheep (Eberhardt et al. 1999) and gilts (Whaley et al. 1997, 2000) the effects of retinol on follicular development were monitored and recorded 4 days post-administration. The reason why these standards were set are not described and the limits (length and dosage) of $\mathrm{ROH}$ treatment are unknown. Furthermore, it would be interesting to determine whether the effects of exogenous $\mathrm{ROH}$ were exerted on the intrafollicular oocyte, the ovulated oocyte, the proper early embryo, or both the oocyte and the embryo.

The ability of blastocysts resulting from oocytes of domestic females treated with exogenous $\mathrm{ROH}$ to establish and maintain pregnancy is unknown. Development of these blastocysts after transfer to recipients is worth testing since disturbances in retinoid homeostasis have been linked to developmental abnormalities (reviewed by Zile 2001). The above questions can be tested in part by treating oocyte donor cows with $\mathrm{ROH}$, as those oocytes aspirated from the follicle would develop free from the effects of circulating $\mathrm{ROH}$ when cultured in vitro up to the blastocyst stage. We have earlier reported that the presence of RA in in vitro maturation (IVM) medium enhanced oocyte maturation, embryo development (Duque et al. 2002a, Gómez et al. 2003, 2004, Hidalgo et al. 2003) and pregnancy rates (Hidalgo et al. 2003). Since $\mathrm{ROH}$ has no effect during IVM at physiological temperature (Duque et al. 2002b, Lawrence et al. 2004) it was necessary to perform an overexposure of the oocytes to retinoid by using RA. Therefore, our study is intended to analyse whether $\mathrm{ROH}$ acts in the cow as early as the oocyte intrafollicular growth period, to contribute to define limits and timing of the oocyte exposure to exogenous $\mathrm{ROH}$, and to determine the efficiency and sustainability of Ovum-Pick Up (OPU) techniques based on $\mathrm{ROH}$ support in terms of oocyte and blastocyst yields and viability of embryos upon transfer to recipients.

\section{Materials and Methods}

Unless otherwise stated, all chemicals were purchased from Sigma and culture media were prepared with MilliQ-water type 1 (Waters, Madrid, Spain).

\section{Animal management}

Asturiana de los Valles heifers aged 17-20 months were fed freely with home-made grass silage, mineral premix, and barley or oat straw along with $1-2 \mathrm{~kg}$ concentrate per day in order to maintain a body condition score of 2.5-3 (scale 1-5, where 1 emaciated and 5 obese). All experimental animals were housed, handled and used in accordance with Spanish national laws. Prior to an OPU session, each animal was restrained in a standing position in a chute and tranquillized with $2 \%$ xilacine $(0.25 \mathrm{ml} / \mathrm{kg}$ live weight of Rompun; Bayer, Barcelona, Spain). Rectum and perineal regions were cleaned and disinfected prior to administering anaesthesia. Epidural anaesthesia was performed using $2 \%$ lidocaine (Laboratorios Ovejero, León, Spain). Subsequent to oocyte aspiration each donor cow received a vaginal wash with povidone-iodine $(10 \%$ Betadine).

\section{Follicle puncture}

To recover oocytes by OPU, ovarian follicles were visualized with a $6.5 \mathrm{MHz}$ convex echographic transducer (PB-06VE65/20BD; Sonovet, Kangwon-do, Korea) connected in parallel to an echo camera/ultrasound scanner SA 600 (Sonovet, Kangwon-do, Korea). The probe incorporated a guide through which a disposable puncture needle was introduced (V-OPAN-1760; Cook Veterinary Products, Queensland, Australia) and attached to Teflon tubing (internal and external diameter: 1.6 and $3.2 \mathrm{~mm}$ respectively). Tubing was connected to a $50 \mathrm{ml}$ collection tube (Corning Inc., NY, USA) and the system was powered by a vacuum pump (V-MAR-5100; Cook Veterinary Products) providing pressure of $85 \mathrm{mmHg}$ (equivalent to a water flow of $14 \mathrm{ml} / \mathrm{min})$. The collection tube was kept at $37^{\circ} \mathrm{C}$ in a heater (V-FTH-2012; Cook Veterinary Products). Before performing the procedure the system was rinsed with collection medium (CM) (TCM199; Invitrogen) with $25 \mathrm{mM}$ Hepes, $0.4 \mathrm{~g} / \mathrm{l}$ BSA Fraction $\mathrm{V}$ and $10 \mathrm{IU} / \mathrm{ml}$ heparin). The flow was periodically monitored and the system was rinsed with CM after the end of the session.

\section{Collection of follicular fluid (FF) and blood, and retinol analysis}

FF aspirated from single follicles were transferred into $1.5 \mathrm{ml}$ Eppendorf tubes. After measuring the aspirate volume the tubes were centrifuged and the supernatant was frozen at $-80{ }^{\circ} \mathrm{C}$ until further analysis. Following each collection, the aspiration circuit was extensively rinsed with physiological saline. 
Blood samples were collected from coccygeal veins using vacutainer tubes containing no additives. Samples were centrifuged and the serum was stored at $-80^{\circ} \mathrm{C}$ until further analysis. $\mathrm{ROH}$ concentration was determined by a quality-controlled HPLC method (Olmedilla et al. 1992). In brief, variable amounts of serum and FF (50$500 \mu \mathrm{l})$ were thawed and deproteinized with ethanol containing an internal standard (retinyl acetate). After vortexing for $45 \mathrm{~s}$, analytes were extracted twice with hexane/methylene chloride $(5: 1 \mathrm{v} / \mathrm{v})$, and the organic phases pooled, evaporated and reconstituted before injection into the HPLC equipment. Chromatographic analysis was carried out on Spheri-5-ODS $(5 \mu \mathrm{m}, 4.6 \times 250 \mathrm{~mm})$ (Applied Biosystems, San José, CA, USA), and isocratic elution was performed with acetonitrile/methylene with acetonitrile/ methylene chloride/methanol (ammonium acetate $0.025 \mathrm{M})(70: 20: 10)$ at a flow rate of $1.3 \mathrm{ml} / \mathrm{min}$. Peak identification was confirmed by chromatographic behaviour and on-line spectra with a 996 Photodiode Array Detector (Waters Associates), compared with those obtained for standards and registered in the Millennium Data Station (Waters Associates). Retinyl acetate and $\mathrm{ROH}$ were detected at $325 \mathrm{~nm}$. Using this protocol our quantification limit was $0.5 \mu \mathrm{g} / \mathrm{dl}$.

Accuracy and precision of the analytical method used was evaluated periodically through participation in the Fat-Soluble Vitamins Quality Assurance Program conducted by the National Institute of Standards and Technology (NIST) (Gaithersburg, MD, USA). Accuracy was within $10 \%$ from assigned values, and within-day and betweenday precision for evaluated analytes during the period of this study, assessed by blind duplicates distributed by NIST, were $<5 \%$ and $<10 \%$ respectively.

\section{Oocyte search and classification}

FF contents form each heifer were filtered (Emcon; Comextrade, Tarragona, Spain), rinsed with ovum culture medium $+5 \%$ fetal calf serum (FCS) and placed in a Petri dish. Intact cumulus-oocyte complexes (COCs) were picked using a stereomicroscope and washed four times in holding medium (HM) (TCM199 + $25 \mathrm{mM}$ Hepes $+0.4 \mathrm{~g} / \mathrm{l}$ $\mathrm{BSA})$. COCs were then classified into four categories based on their morphological appearance at $\times 60$ : (1) complete and compact cumulus, having at least four complete layers of clear cells; (2) complete but less compact cumulus, with at least four cell layers, or abnormally dark cells; (3) incomplete or expanded cumulus; and (4) denuded oocytes. Degenerated and broken oocytes were recorded but excluded from culture.

\section{In vitro embryo production}

For IVM, we used a basic maturation medium (MM) consisting of $\mathrm{TCM}_{199}+\mathrm{NaHCO}_{3} \quad(2.2 \mathrm{~g} / \mathrm{l})+$ porcine follicle-stimulating hormone $(\mathrm{FSH}) \quad(1 \mu \mathrm{g} / \mathrm{ml})+$ luteinizing hormone (LH) $(5 \mu \mathrm{g} / \mathrm{ml})+17 \beta$-oestradiol
$(1 \mu \mathrm{g} / \mathrm{ml})+$ poly vinyl alcohol (PVA) $(0.5 \mathrm{mg} / \mathrm{ml})$. After two washes in $M M$ and a new wash in the medium assigned to each group, COCs were matured in $500 \mu \mathrm{l}$ MM in four-well dishes (Nunc, Roskilde, Denmark) for $22-24 \mathrm{~h}$ at $39^{\circ} \mathrm{C}$, in an atmosphere containing $5 \% \mathrm{CO}_{2}$ and saturated humidity. All categories of COCs described were used for IVM.

For in vitro fertilization (IVF), motile spermatozoa were separated by a swim-up procedure similar to that reported by Parrish et al. (1986). Frozen-thawed semen was layered into $1 \mathrm{ml}$ sperm Tyrode-albumin-lactate-pyruvate (TALP) and incubated for $1 \mathrm{~h}$. The upper $700 \mathrm{ml}$ containing motile spermatozoa was centrifuged for $7 \mathrm{~min}$ at $100 \mathrm{~g}$ and the supernatant was aspirated leaving a pellet of approximately $100 \mu \mathrm{l}$ in volume. Spermatozoa concentration was then determined using a haemocytometer. The COCs were washed twice in HM, twice in pre-equilibrated fertilization medium (Fert-TALP), and placed in four-well culture dishes containing Fert-TALP with heparin $(10 \mu \mathrm{g} / \mathrm{ml})$ (Calbiochem, La Jolla, CA, USA). Spermatozoa were then added at a concentration of $2 \times 10^{6}$ cells $/ \mathrm{ml}$ in $500 \mu \mathrm{l}$ of medium per well. IVF was accomplished by incubating oocytes and spermatozoa together for 18-20 h at $39^{\circ} \mathrm{C}$ in $5 \% \mathrm{CO}_{2}$ under high humidity.

For in vitro embryo culture, presumptive zygotes were gently passed back and forth through a small-gauge pipette to remove cumulus cells and sperm, washed three times in $\mathrm{HM}$ and twice in culture medium. Embryo culture was performed in modified synthetic oviduct fluid ( $285 \mathrm{mOsm}, \mathrm{pH}$ 7.2-7.3) containing amino acids, citrate and myo-inositol (Holm et al. 1999). FCS was added to the embryo culture media $42 \mathrm{~h}$ post-fertilization (PI). Droplets of culture medium $(1-2 \mu \mathrm{l} / \mathrm{embryo})$ were prepared in four-well dishes under mineral oil and equilibrated for $2 \mathrm{~h}$ before addition of zygotes. Incubations were carried out at $39^{\circ} \mathrm{C}$ in $5 \%$ $\mathrm{CO}_{2}, 5 \% \mathrm{O}_{2}$ and $90 \% \mathrm{~N}_{2}$. Culture media were renewed at $66 \mathrm{~h}$ (Day 3) and $138 \mathrm{~h}$ (Day 6) $\mathrm{Pl}$, and embryonic development was recorded on Days 3, 6, 7 and 8.

\section{Embryo transfer (ET)}

Day 7 blastocysts were selected for ET. Embryos transferred fresh included unexpanded and expanded blastocysts, while embryos transferred after vitrification and warming were predominantly expanded blastocysts. For vitrification, embryos were loaded into straws containing PBS (Invitrogen) with glycerol, ethylene glycol and FCS, adjacent to two fractions of galactose solution (Kaidi et al. 2001). Embryos were warmed for $5 \mathrm{~s}$ in air and $10 \mathrm{~s}$ in a water bath at $30^{\circ} \mathrm{C}$. The contents of each straw were emptied into a Petri dish and embryos were mixed in the galactose solution by slight agitation. After $5 \mathrm{~min}$, the embryos were transferred to another Petri dish containing PBS $+20 \%$ FCS for 5 min. Embryos were then allowed to re-expand in B2 INRA Ménézo (C.C.D., Paris, France) at $39^{\circ} \mathrm{C}$ in an incubator. Finally, re-expanded embryos were loaded into $0.25 \mathrm{ml}$ straws 
and non-surgically transferred into synchronized recipients, aged 15-18 months.

\section{Experimental design}

\section{Experiment 1: $\mathrm{ROH}$ concentration in blood and FF} after administration of $\mathrm{ROH}$

We first studied short-term responses to a single $\mathrm{ROH}$ injection using 12 heifers. Oestrus was synchronized with progestagen (Crestar; Intervet, Salamanca, Spain) and then followed with an injection of prostaglandin $F_{2} \alpha$ (Estrumate; Shering-Plough, Kenilworth, New Jersey, USA) given on Day -2 of the subsequent cycle. Blood samples were first taken at the time of progestagen removal (Day 0 ), just prior to treatment administration. Animals were then injected with $1 \times 10^{6} \mathrm{IU} \mathrm{ROH}$ (Fluka 95144; Madrid, Spain) $(n=6)$ or corn oil (vehicle; $n=6$ ) on Day 0. Blood samples were taken again on Day +1 and Day +4 , and contents of single follicles measuring between 3 and $10 \mathrm{~mm}$ in diameter were aspirated on Day +4 , and the recovered FF volume was measured. Blood plasma and FF were analysed for $\mathrm{ROH}$.

\section{Experiment 2: Influence of exogenous $\mathrm{ROH}$ on oocyte production and development}

This experiment was performed to investigate the effect of repeated OPU sessions following $\mathrm{ROH}$ administration. Oocyte donors $(n=26)$ were subjected to one cycle of eight OPU sessions without superovulation at alternating intervals of 3 and 4 days, as can be seen in Table 1 . Animals were injected with $1 \times 10^{6} \mathrm{IU} \mathrm{ROH}(n=13) 4$ days before the first session and at the end of the second, fourth and sixth sessions. Four days later, a second OPU cycle of eight sessions started without $\mathrm{ROH}$ stimulation. Control groups of heifers $(n=13)$ received corn oil (vehicle) during the first cycle and were not treated in the second

Table 1 Recovery of oocytes and injection and sampling routine followed during Experiment 2.

\begin{tabular}{llcl}
\hline Day & OPU cycle & Session & Routine \\
\hline-4 & & & $\mathrm{I}+\mathrm{B}$ \\
0 & ROH-stimulated & 1 & $\mathrm{~B}$ \\
3 & & 2 & $\mathrm{I}+\mathrm{B}$ \\
7 & & 3 & $\mathrm{~B}$ \\
10 & 4 & $\mathrm{I}+\mathrm{B}$ \\
14 & 5 & $\mathrm{~B}$ \\
17 & & 6 & $\mathrm{I}+\mathrm{B}$ \\
21 & & 7 & $\mathrm{~B}$ \\
24 & Non-ROH-stimulated & 8 & $\mathrm{~B}$ \\
28 & & 1 & $\mathrm{~B}$ \\
31 & & 2 & - \\
35 & & 3 & $\mathrm{~B}$ \\
38 & & 4 & - \\
42 & 5 & $\mathrm{~B}$ \\
45 & & 6 & - \\
49 & & 7 & $\mathrm{~B}$ \\
52 & & 8 & - \\
\hline
\end{tabular}

I: $\mathrm{ROH}$ or vehicle injection; $\mathrm{B}$ : blood sampling for $\mathrm{ROH}$ analysis. cycle. Blood plasma was analysed for $\mathrm{ROH}$ twice per week during the first cycle and once per week during the second cycle. Visible follicles were counted and aspirated. Recovered COCs were counted and classified as mentioned earlier. COCs obtained from similarly treated donors were pooled and assigned to each of two IVM groups that contained either 0 or $0.5 \mu \mathrm{M}$ 9-cis-RA in a $2 \times 2$ factorial design, according to $\mathrm{ROH}$-treated donors. Variables monitored were follicle counts, oocytes recovered, oocyte quality and oocytes selected for IVM; cleaved zygotes and embryos with more than eight cells on Day 3; and blastocyst development on Day 7 and Day 8. Cows were managed in groups of four and six animals, and the experiment was repeated five times. Cultures with no embryonic development in all groups were not considered for analysis. Three donors could not be used beyond the fourth session in the first cycle, and two more donors during the entire second cycle because of clinical problems.

\section{Experiment 3: Influence of exogenous $\mathrm{ROH}$ on blastocyst viability after $E T$}

Embryos transferred were produced from oocytes within the first six OPU sessions in all experimental groups from Experiment 2. Recipients received either one fresh embryo or two vitrified embryos transferred into the uterine horn adjacent to a corpus luteum. Pregnancy diagnosis was confirmed using plasma progesterone (P4) concentrations $(>2.5 \mathrm{ng} / \mathrm{ml})$ on Day 21 and ultrasonographic scanning on Day 35 and subsequently at Day 60.

\section{Statistical analysis}

Data from follicle numbers, oocyte production and embryo development were analysed in two steps. First, since these values can be represented by contingency tables, those factors significantly affecting the variables were identified by means of the procedure Categorical Data Modelling (CATMOD) (SAS Version 8.2 1999; SAS Institute Inc., Cary, NC, USA). CATMOD extends analysis from continuous data to categorical data, fitting linear models to functions of response frequencies. Treatment and replicate were found to have significant influence on dependent variables. Secondly, those factors identified to be significant were used to fit a linear model using the procedure General Linear Models (GLM) (SAS). This procedure performs ANOVA for unbalanced data. GLM was used to estimate least square means (LSM) for each fixed effect having a significant F value. Duncan's multiplerange test was carried out on raw means calculated for the main effects on embryo development. LSMs for monitored follicles, oocyte production and embryonic development, are expressed as absolute average values on a per donor and per treatment basis, although embryonic development data were as well referred to frequency percentages of oocytes in IVM. Significant interactions between $\mathrm{ROH}$ and RA were detected by means of CATMOD. GLM 
was used to reject the null hypothesis $\left(\mathrm{H}_{0}: \mathrm{LSM}_{(\mathrm{i})}=\mathrm{LSM}_{(\mathrm{j})}\right)$ for LSMs within interaction levels. Data for $\mathrm{ROH}$ concentrations were processed by GLM-ANOVA and Duncan's test. Pregnancy data were submitted to chi-square test of homogeneity for each stratum of treatment-day of pregnancy, and results refer to absolute frequencies.

\section{Results}

\section{Experiment 1}

In heifers not submitted to OPU (i.e. short-term responses), blood concentrations of $\mathrm{ROH}$ increased $24 \mathrm{~h}$ after $\mathrm{ROH}$ injection (Fig. 1), and this rise was cleared 4 days after injection. On Day +4 , one single follicle was aspirated per cow $(n=12)$ and, interestingly, $\mathrm{ROH}$ concentration was higher in follicles in cows treated with $\mathrm{ROH}$ compared with controls. Stage of the oestrous cycle did not influence blood and FF ROH concentrations. The average FF volume recovered was $393 \pm 127 \mu$ l (range 80-950) and $351 \pm 127 \mu \mathrm{l}$ (range 100-700) for $\mathrm{ROH}$ and oil-treated heifers respectively $(P>0.8)$, and the measured volume of FF correlated with $\mathrm{ROH}$ concentrations $(r=0.70, P=0.034)$.

During the OPU cycles (Table 1), the samples were recovered at the end of each session in the first cycle (twice per week) and after the first, third, fifth and seventh sessions within the second cycle (once per week). Exogenous administration of $\mathrm{ROH}$ gave no differences $(P>0.15)$ between and within the treated first cycle and the untreated second cycle (Table 2).

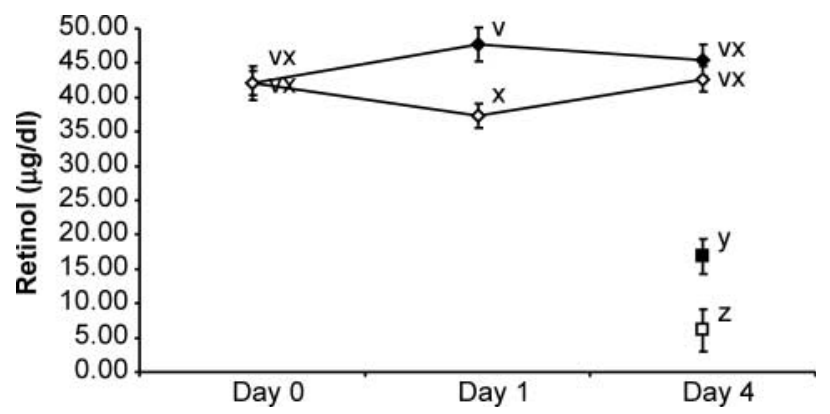

Figure 1 Short-term changes in retinol concentrations in blood (diamonds) and ovarian follicle (squares) from cows injected with retinol (black) or vehicle (open). Error bars show LSM \pm S.E. $\left({ }^{v, x, y, z} P<0.01\right)$

Table 2 Average retinol blood concentrations in oocyte donor cows during the first cycle treated with retinol (weekly injected with $1 \times 10^{6} \mathrm{IU}$ retinol or corn oil as vehicle during eight OPU sessions), and a second untreated cycle consisting of eight OPU sessions.

\begin{tabular}{llcl}
\hline Cycle & Group & Cows $(n)$ & Retinol $(\mu g / \mathrm{dl})$ \\
\hline 1st (treated) & ROH & 5 & $24.77 \pm 1.55$ \\
2nd (untreated) & ROH & & $22.28 \pm 1.52$ \\
1st (treated) & Oil & 6 & $24.74 \pm 1.83$ \\
2nd (untreated) & Oil & & $25.93 \pm 1.70$ \\
\hline
\end{tabular}

Values are $\mathrm{LSM} \pm$ S.E. $(P>0.05)$

\section{Experiment 2}

Responses to ROH throughout cycles 1 and 2, in terms of follicles monitored and oocytes recovered are plotted in Fig. $2 \mathrm{a}$ and b. A gradual decrease in follicle numbers and oocytes recovered, although independent from treatment, was observed. Overall, the first cycle was more productive than the second cycle (Table 3), and $\mathrm{ROH}$ injected within the first cycle had no significant influence on subsequent oocyte production during the second cycle. More lowquality oocytes were harvested in the first cycle from donors treated with $\mathrm{ROH}$.

Overall embryonic development within both OPU cycles is showed in Table 4. While no differences could be observed between cleavage and the five to eight cell stage (not shown in Table), embryos matured with RA showed higher developmental kinetics on Day 3, as more embryos developed to the $8-16$ cell stage. During the first cycle, RA increased the formation of morula but did not increase blastocyst formation rates. However, cumulatively, RA did increase blastocyst rates.

When oocyte production was studied on a cumulative session basis, we found that significant responses to $\mathrm{ROH}$ were obtained in sessions one to five within the first cycle (Table 5). Anticipating overall results, COCs yields within the $\mathrm{ROH}$ group accounted for higher numbers of lowquality recovered COCs (categories 3 and 4), as well as for higher follicle numbers. Interestingly, more morulae and blastocysts developed from oocytes collected during sessions one to five from $\mathrm{ROH}$-treated animals (Table 6). On the other hand, embryonic development observed with oocytes obtained from control animals treated with $\mathrm{RA}$ was even better than those observed with $\mathrm{ROH}$-treated animals. Differences were not observed later than session five since oocytes recovered in subsequent sessions during both the first and second cycle did not respond to RA.

\section{Experiment 3}

Embryos derived from cows treated with $\mathrm{ROH}$ were unable to establish a viable pregnancy (Table 7). As shown by low P4 levels on Day 21, development of transferred blastocysts was most probably disrupted before implantation. Pregnancy rates were independent of whether fresh or vitrified embryos were transferred.

\section{Discussion}

In the live animal, $\mathrm{ROH}$ is transported in the blood bound to RBP and depending on the requirement is delivered to the target tissues for metabolism to RA. Therefore, the influence of $\mathrm{ROH}$ on follicular and oocyte growth could have been exerted through its conversion to RA following its uptake from the plasma. The RA thus formed in the follicular cells can exert its action by binding to and activating specific RA receptors. In the present study, cows injected with $\mathrm{ROH}$ developed follicles containing high 

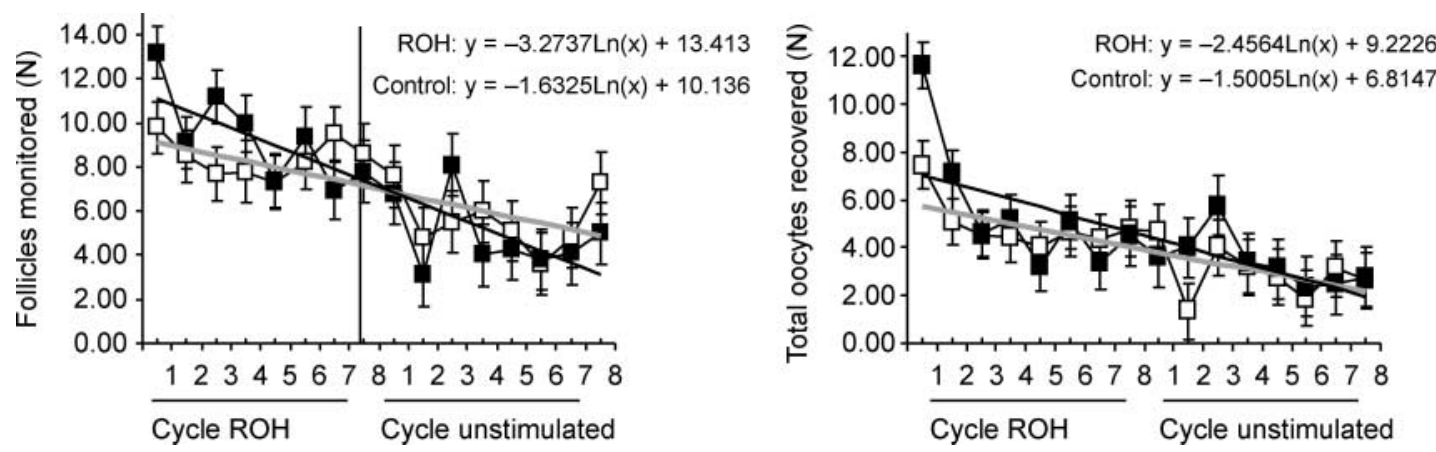

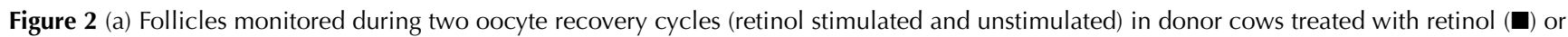

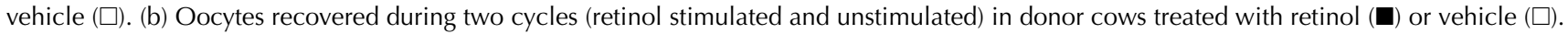
( $\mathrm{ROH}$ data, black regression line; Control data, grey regression line).

Table 3 Monitored follicles and oocyte production during the 1st and 2nd cycle of eight sessions from oocyte donor cows treated with ROH or corn oil and a 2 nd cycle of eight sessions without treatment.

\begin{tabular}{|c|c|c|c|c|c|c|c|c|c|}
\hline \multirow[b]{2}{*}{ Cycle } & \multirow[b]{2}{*}{ Group } & \multirow[b]{2}{*}{ Cows $(n)$} & \multirow[b]{2}{*}{$\mathbf{S}$} & \multirow[b]{2}{*}{$\mathbf{N}$} & \multirow[b]{2}{*}{ Follicles } & \multicolumn{4}{|c|}{ Average COCs } \\
\hline & & & & & & HQ & LQ & Cultured & Total \\
\hline 1st (treated) & $\mathrm{ROH}$ & 13 & 89 & 517 & $9.52^{\mathrm{a}}$ & $2.68^{\mathrm{a}}$ & $2.90^{\mathrm{a}}$ & $5.59^{\mathrm{a}}$ & $5.92^{\mathrm{a}}$ \\
\hline 1st (treated) & Oil & 13 & 91 & 458 & $8.56^{\mathrm{a}}$ & $2.61^{\mathrm{a}}$ & $2.16^{\mathrm{b}}$ & $4.77^{\mathrm{a}}$ & $5.15^{a}$ \\
\hline 2nd (untreated) & $\mathrm{ROH}$ & 10 & 63 & 199 & $5.87^{\mathrm{b}}$ & $1.75^{\mathrm{b}}$ & $1.35^{\mathrm{c}}$ & $2.98^{\mathrm{b}}$ & $3.20^{\mathrm{b}}$ \\
\hline 2nd (untreated) & Oil & 11 & 72 & 225 & $5.38^{\mathrm{b}}$ & $1.51^{\mathrm{b}}$ & $1.22^{\mathrm{C}}$ & $2.87^{\mathrm{b}}$ & $3.07^{\mathrm{b}}$ \\
\hline
\end{tabular}

$\overline{a, b, c}(P<0.03) . S=$ number of sessions. $\mathrm{N}=$ total oocytes recovered. HQ: COCs quality 1 and 2; LQ: COCs quality 3 and 4.

Table 4 Developmental competence of oocytes obtained during the first OPU cycle consisting of eight sessions from donor cows treated with $\mathrm{ROH}$ or corn oil (vehicle, controls) and during the 2 nd cycle consisting of eight sessions without treatment following in vitro maturation with or without 9-cis retinoic acid (RA).

\begin{tabular}{|c|c|c|c|c|c|c|c|}
\hline \multirow[b]{2}{*}{ OPU cycle } & \multirow[b]{2}{*}{$\mathbf{R O H}(\mathrm{cow})$} & \multirow[b]{2}{*}{ RA (IVM) } & \multicolumn{2}{|c|}{ Day 3 (\%) } & \multirow[b]{2}{*}{ Day 6 morulae (\%) } & \multicolumn{2}{|c|}{ Blastocysts (\%) } \\
\hline & & & Cleaved & $8-16$ cells & & Day 7 & Day 8 \\
\hline 1 & Oil & - & $64.5 \pm 5.2$ & $3.7 \pm 2.1$ & $12.9 \pm 4.0^{\mathrm{a}}$ & $7.3 \pm 2.6$ & $8.9 \pm 2.8$ \\
\hline 1 & Oil & + & $62.9 \pm 5.2$ & $8.6 \pm 2.1$ & $31.1 \pm 4.0^{\mathrm{b}}$ & $13.3 \pm 2.6$ & $15.1 \pm 2.8$ \\
\hline 1 & + & - & $56.2 \pm 5.2$ & $2.5 \pm 2.1^{\mathrm{a}}$ & $22.4 \pm 4.0$ & $10.7 \pm 2.6$ & $10.8 \pm 2.8$ \\
\hline 1 & + & + & $63.7 \pm 5.2$ & $4.4 \pm 2.1$ & $22.1 \pm 4.0$ & $10.5 \pm 2.6$ & $11.8 \pm 2.8$ \\
\hline 2 & - & - & $70.4 \pm 6.7$ & $3.4 \pm 2.6$ & $25.7 \pm 5.0$ & $6.9 \pm 3.6$ & $8.1 \pm 3.9$ \\
\hline 2 & - & + & $64.1 \pm 6.8$ & $10.3 \pm 2.7^{\mathrm{b}}$ & $20.3 \pm 5.0^{\mathrm{a}}$ & $13.3 \pm 3.6$ & $15.0 \pm 3.9$ \\
\hline 2 & + & - & $71.5 \pm 7.0$ & $3.3 \pm 2.8$ & $24.2 \pm 5.1$ & $9.5 \pm 3.6$ & $11.9 \pm 3.9$ \\
\hline 2 & + & + & $70.3 \pm 7.1$ & $3.0 \pm 2.8^{\mathrm{a}}$ & $27.6 \pm 5.3$ & $9.6 \pm 3.6$ & $10.5 \pm 3.9$ \\
\hline \multicolumn{8}{|l|}{ Cumulative } \\
\hline $1+2$ & - & - & $66.0 \pm 4.2$ & $3.5 \pm 1.6^{x}$ & - & $7.2 \pm 2.1^{\mathrm{a}}$ & $8.7 \pm 2.3^{\mathrm{a}}$ \\
\hline $1+2$ & - & RA & $64.9 \pm 4.2$ & $9.3 \pm 1.7^{y}$ & - & $13.3 \pm 2.1^{\mathrm{b}}$ & $15.1 \pm 2.3^{\mathrm{b}}$ \\
\hline $1+2$ & $\mathrm{ROH}$ & - & $61.3 \pm 4.3$ & $2.8 \pm 1.7^{x}$ & - & $10.4 \pm 2.1$ & $11.9 \pm 2.3$ \\
\hline $1+2$ & $\mathrm{ROH}$ & RA & $63.1 \pm 4.3$ & $3.8 \pm 1.7^{x}$ & - & $10.3 \pm 2.1$ & $10.7 \pm 2.3$ \\
\hline
\end{tabular}

${ }_{\mathrm{a}, \mathrm{b}} P=0.055 ;{ }^{\mathrm{x}, \mathrm{y}} \mathrm{P}<0.01$.

Table 5 Follicles monitored, COC recovery rate, their numbers and quality in oocyte donor cows treated with ROH or vehicle during sessions 1 to 5 within the 1 st $\mathrm{ROH}$-stimulated cycle.

\begin{tabular}{|c|c|c|c|c|c|c|c|c|c|}
\hline \multirow[b]{2}{*}{ Group } & \multicolumn{3}{|c|}{ Sessions 1-5 } & \multirow[b]{2}{*}{ Follicles ( $n /$ session) } & \multirow[b]{2}{*}{ Recovered COCs $(\%)$} & \multicolumn{4}{|c|}{$\operatorname{COCs}(n)$} \\
\hline & Cows & OPU & COCs & & & HQ & LQ & Cultured & Total \\
\hline $\mathrm{ROH}$ & 13 & 53 & 350 & $10.3 \pm 0.6^{\mathrm{a}}$ & $63.0 \pm 4.4$ & $2.6 \pm 0.3$ & $3.4 \pm 0.2^{\mathrm{x}}$ & $6.1 \pm 0.4^{\mathrm{a}}$ & $6.5 \pm 0.5^{\mathrm{a}}$ \\
\hline Control & 13 & 55 & 270 & $8.3 \pm 0.6^{b}$ & $57.0 \pm 4.4$ & $2.4 \pm 0.3$ & $2.4 \pm 0.2^{y}$ & $4.8 \pm 0.4^{b}$ & $5.1 \pm 0.5^{b}$ \\
\hline
\end{tabular}

Different superscripts differ significantly: ${ }^{a, b} P<0.03 ;{ }^{x, y} P<0.01$. Recovered COCs are a percentage of number of follicles observed. OPU: number of OPU sessions. Values refer to a session average; HQ: COCs quality 1 and 2; LQ: COCs quality 3 and 4. 
Table 6 Embryonic development of oocytes obtained during sessions 1 to 5 from cows treated with all-trans retinol (ROH) or corn oil (vehicle) and matured with or without 9-cis retinoic acid (RA).

\begin{tabular}{|c|c|c|c|c|c|c|c|c|c|c|}
\hline \multicolumn{2}{|c|}{ Treatment } & \multicolumn{3}{|c|}{ Sessions $1-5$} & \multicolumn{2}{|c|}{ Morulae (Day 6) } & \multicolumn{2}{|c|}{ Blastocysts (Day 7) } & \multicolumn{2}{|c|}{ Blastocysts (Day 8) } \\
\hline Cow & IVM & $\mathrm{D}$ & OPU & $\mathrm{COC}$ & $\mathrm{N}$ & $\%$ & $\mathrm{~N}$ & $\%$ & $\mathrm{~N}$ & $\%$ \\
\hline Oil & - & 13 & 28 & 128 & $0.61 \pm 0.3^{x}$ & $7.9 \pm 4.4^{x}$ & $0.28 \pm 0.2^{\mathrm{a}}$ & $2.9 \pm 2.8^{\mathrm{ax}}$ & $0.36 \pm 0.3$ & $4.7 \pm 3.0^{\mathrm{a \alpha}}$ \\
\hline Oil & RA & & 27 & 142 & $2.05 \pm 0.2^{y}$ & $38.2 \pm 4.4^{\text {ay }}$ & $1.10 \pm 0.2^{\mathrm{b}}$ & $20.3 \pm 2.8^{\text {by }}$ & $1.11 \pm 0.3$ & $22.0 \pm 3.0^{\mathrm{b} \beta}$ \\
\hline $\mathrm{ROH}$ & - & 13 & 26 & 169 & $2.08 \pm 0.3^{y}$ & $24.8 \pm 4.4^{\text {by }}$ & $1.01 \pm 0.2$ & $12.3 \pm 2.8^{\mathrm{c}}$ & $1.12 \pm 0.3$ & $13.1 \pm 3.0^{\mathrm{C}}$ \\
\hline $\mathrm{ROH}$ & RA & & 27 & 181 & $2.00 \pm 0.2^{y}$ & $24.7 \pm 4.4^{\text {by }}$ & $0.95 \pm 0.2$ & $11.6 \pm 2.8^{\mathrm{c}}$ & $1.05 \pm 0.3$ & $11.6 \pm 3.0^{\mathrm{C}}$ \\
\hline
\end{tabular}

D: number of donors; OPU: number of OPU sessions; COC: number of COCs cultured. Data are either average embryos obtained per treatment and session ( $\mathrm{N}$ : corrected by COCs cultured within the same cow treatment), or proportions of matured oocytes (\%). Different superscripts in the same column differ significantly: ${ }^{\mathrm{a}, \mathrm{b}, \mathrm{c}} P<0.05 ;{ }^{\mathrm{x}, \mathrm{y}} \mathrm{P}<0.01 ;{ }^{\alpha, \beta} P<0.001$.

Table 7 Pregnancy rates after the transfer to heifers of fresh (one embryo/recipient) or vitrified (V) (two embryos/recipient) bovine blastocysts produced in vitro using oocytes recovered from donor cows treated with all-trans retinol $(\mathrm{ROH})$ or corn oil (vehicle; negative controls $(-)$, and matured in defined medium TCM199-PVA and hormones) with (+) or without (-) 9-cis-retinoic acid (RA).

\begin{tabular}{|c|c|c|c|c|c|c|c|}
\hline \multirow[b]{2}{*}{ Cow } & \multirow[b]{2}{*}{ IVM } & \multicolumn{2}{|c|}{ Embryos transferred } & \multirow[b]{2}{*}{ ETs $(n)$} & \multicolumn{3}{|c|}{ Pregnancy (\%) } \\
\hline & & Fresh & Vitrified & & Day 21 & Day 35 & Day 60 \\
\hline $\mathrm{ROH}$ & - & 5 & 12 & 11 & $0^{\mathrm{a}}(0 / 11)$ & $0^{\mathrm{a}}$ & $0 *$ \\
\hline $\mathrm{ROH}$ & RA & 1 & 6 & 4 & $0^{a}(0 / 4)$ & $0^{\mathrm{a}}$ & $0 *$ \\
\hline- & - & 4 & 6 & 7 & $43(3 / 7)(1 \mathrm{~V})$ & $14(1 / 7)(1 \mathrm{~V})$ & $0 *$ \\
\hline- & RA & 8 & 6 & 11 & $45^{\mathrm{b}}(5 / 11)(1 \mathrm{~V})$ & $45^{b}(5 / 11)(1 \mathrm{~V})$ & $36 * *(4 / 11)(1 \mathrm{~V})$ \\
\hline \multicolumn{8}{|c|}{ Cumulative } \\
\hline $\mathrm{ROH}$ & - & 6 & 18 & 15 & $0^{\mathrm{x}}(0 / 15)$ & $0^{x}$ & - \\
\hline- & - & 12 & 12 & 18 & $44^{y}(8 / 18)$ & $33^{y}(6 / 18)$ & - \\
\hline
\end{tabular}

Pregnancy diagnosis: Day 21, P4 concentrations $>4 \mathrm{ng} / \mathrm{ml}+$ no oestrus; Days 35 and 60, ultrasound scanning; different superscripts within columns statistically differ: ${ }^{\mathrm{x}, y} P<0.02 ;{ }^{\mathrm{a}, \mathrm{b}} P<0.05 ; *, * * P=0.07$.

A proportion of control embryos transferred and their pregnancy rates were published in Hidalgo et al. (2003) reporting that RA during IVM increases pregnancy rates. These data are used in the present experiments merely as positive controls; they are not treated as results and do not form part of the discussion by themselves.

FF ROH concentrations while maintaining normal concentrations in the blood. This suggests that the follicle is able to incorporate $\mathrm{ROH}$ in less than 4 days following exogenous administration. This increase substantiates the administration of $\mathrm{ROH}$ at least 4 days before an effect is expected. Concentrations of $\mathrm{ROH}$ in FF appeared to be lower in our control group than has been reported by others for untreated animals (Chew et al. 1984, Schweigert et al. 1986, Haliloglu et al. 2002). However, the FF $\mathrm{ROH}$ concentrations in the treated group fell within the above reported range for untreated animals (Chew et al. 1984, Schweigert et al. 1986, Haliloglu et al. 2002). In addition, mean $\mathrm{ROH}$ blood concentrations in our study, in both $\mathrm{ROH}$-treated and controls, are in agreement with previous reports (Chew et al. 1984, Schweigert et al. 1986, Frye et al. 1991, Velasquez-Pereira et al. 1998, Haliloglu et al. 2002, Katamoto et al. 2003). During all OPU cycles, $\mathrm{ROH}$ values did not differ between treatments and between cycles, providing evidence that blood $\mathrm{ROH}$ regulatory mechanisms were not influenced by repeated $\mathrm{ROH}$ injections. It is possible that supplementary $\mathrm{ROH}$ was either stored or compartmentalized (FF). Using Holstein cattle, Haliloglu et al. (2002) found differences in $\mathrm{ROH}$ concentrations between blood and FF only during the oestrous phase of the cycle and no differences were observed during other phases of the oestrous cycle. In agreement with the findings of Schweigert et al. (1986), the concentration of $\mathrm{ROH}$ in the blood was higher than in $\mathrm{FF}$, especially towards the beginning of dioestrus. Contrary to the findings of Haliloglu et al. (2002), we detected a positive correlation between $\mathrm{FF}$ volume and $\mathrm{ROH}$ as reported by others (Schweigert et al. 1986, Schweigert \& Zucker 1988). The ability to take up $\mathrm{ROH}$ possibly indicates that the follicles were healthy and viable as nonatretic large follicles during the oestrous phase have the highest concentrations of $\mathrm{ROH}$ (Schweigert \& Zucker 1988). Unlike in the pig, in the present study, the volume of FF recovered was not influenced by retinoid treatment as reported in pigs (Whaley et al. 2000).

Gonadotrophins such as FSH either alone (Bousquet et al. 1999, Goodhand et al. 1999, Sirard et al. 1999) or in combination with LH (Blondin et al. 2002, see a review by Merton et al. 2003) and pregnant mare serum gonadotrophin (Pieterse et al. 1991) have been used to improve the outcome of OPU in adult donor cows. Oocytes from superovulated cows are developmentally more competent than their non-stimulated counterparts (Faber et al. 2003, Merton et al. 2003), and specific changes in superovulatory treatment can greatly increase developmental competence of the oocyte (Blondin et al. 2002). However, due to high variability among gonadotrophin batches and being an animal product we considered $\mathrm{ROH}$ as a potential 
alternative or complementary treatment to hormonal stimulation. In addition, OPU performed at 3- or 4-day intervals is a scheme that can be used for up to 4 consecutive months (Petyim et al. 2003) and has been shown to yield more oocytes per session and embryos from each oocyte batch collected at 3-day intervals (Merton et al. 2003), although we found no significant differences between same intervals (data non shown). Our hypothesis is further supported by the fact that retinoid treatment has been previously shown to increase litter size in the gilt (Brief \& Chew 1983, Coffey \& Britt 1993) and rabbit (Besenfelder et al. 1996), and improve embryonic quality without modifying ovulation rates (Shaw et al. 1995) in superovulated cows (Shaw et al. 1995) and ewes (Eberhardt et al. 1999).

During the first oocyte recovery sessions $\mathrm{ROH}$ increased the total number of monitored follicles and aspirated oocytes. However, most of the oocytes recovered were of low quality. In the present study we found that oocyte donors were more responsive to $\mathrm{ROH}$ following the first three doses, giving us some indication regarding the optimal length of $\mathrm{ROH}$ treatment. Oocytes from cows treated with $\mathrm{ROH}$ showed reduced morulae and blastocysts formation rates, analogous to that seen in an earlier study with oocytes continuously stimulated with RA during IVM in the presence of a meiotic inhibitor (Duque et al. 2002). It has been described that resistance to RA, a phenomenon involving a multifactorial aetiology that is not very well understood, develops rapidly (Marill et al. 2003) and could be involved in decreased late responses observed in our cows and oocytes. Higher transition rates by the eight cell stage were observed with in vivo embryos from ewes treated with ROH (Eberhardt et al. 1999), but in our study we did not observe this effect with $\mathrm{ROH}$. Nevertheless, the $\mathrm{ROH}$ metabolite RA gave more embryos produced by OPU at the 8-16 cell stage on Day 3. This effect was not observed in our previous experiments with slaughterhouse oocytes, so it probably depends on heterogeneous quality within cultured oocytes and/or the OPU procedure itself. The oocyte transcriptional machinery and protein synthesis can be altered by RA stimulation through activating specific genes such as midkine (Gómez et al. 2003). The recombinant peptide product of midkine exerts beneficial effects on embryonic development when added during IVM (Ikeda et al. 2000a,b), although it is also an intermediary candidate in the induction of developmental alterations (Griffith \& Zile 2000). The stimulation by RA at IVM triggers a more physiological cytoplasmic granule migration (Duque et al. 2002) and increases oocyte poly-adenylation, suggesting superior mRNA quality and increased processing (Gómez et al. 2004). This coincides with unaltered expression levels of cyclins B1 and $\mathrm{H} 1$, specific genes regulating the cell cycle, and less oxidative damage (Gómez et al. 2004). Altogether, the above findings correspond to more developmentally competent oocytes (Duque et al. 2002, Hidalgo et al. 2003). The ovarian response to FSH and $\mathrm{LH}$ can also be modulated by RA. In response to this retinoid, stimulation of steroidogenesis (Bugavandoss \& Midgley 1988, Graves-Hoagland et al. 1988), and restricted expression of $\mathrm{FSH}$ receptor $(\mathrm{FSHr})$ in rat granulosa cells has been reported (Minegishi et al. 1996, 2000), which could affect oocyte growth and in turn the outcome of OPU in the cow (Argov et al. 2004). In the porcine, the effects are controversial, as exposure of immature granulosa cells to RA inhibited expression of $\mathrm{LH}$ receptor $(\mathrm{LHr})$ by downregulation of c-Fos mRNA (Hattori et al. 2000). In addition, feeding gilts with $\mathrm{ROH}$ did not affect $\mathrm{P} 4$ secretion by granulosa cells with or without $\mathrm{LH}$ stimulation (Whaley et al. 2000). In the bovine, decreased levels of FSHr and $\mathrm{LHr}$ in cumulus-granulosa cells have been shown to be associated with low-quality oocytes (Calder et al. 2003). In the presence of $\mathrm{RA}$, the growth hormone $(\mathrm{GH})$ receptor $(\mathrm{GHr})$ gene increases transcription (Ohlsson et al. 1993, Slootweg et al. 1996). The transcript of the $\mathrm{GHr}$ was demonstrated in oocytes, follicular cells and the corpus luteum of the bovine ovary (Kolle et al. 1998), and GH was found to stimulate the bovine oocyte during IVM via cumulus cells (Izadyar et al. 1997, Kolle et al. 2003).

In the present study, development of blastocysts from cows that received multiple $\mathrm{ROH}$ injections was disrupted before implantation. This is in contrast to pregnancies obtained when RA was present during IVM (Hidalgo et al. 2003), as these embryos were able to survive beyond the expected time for completion of organogenesis (Day 42) (Hubbert 1974). Vitamin A deficiency and excess can adversely affect the development of the vertebrate embryo as almost every organ or tissue can be affected if there is an imbalance in RA homeostasis during certain critical stages of development (reviewed by Zile 2001). Adequate metabolic systems must inactivate unused RA in order to maintain a stringent retinoid balance, as additional RA synthesis by the embryo is essential for post-implantation development (Niederreither et al. 1999). Most studies on retinoids have focused on later stages of embryonic development, although exposure of zygotes to RA during early embryonic development yields anomalies during pre-gastrulation and organogenesis (Rutledge 1997). Recently, RA treatment during the pre-implantation period in the mouse (Huang et al. 2001, 2003) was shown to cause developmental retardation, inhibition of cell proliferation and induction of apoptosis. In previous reports, development of blastocysts to term was not analysed (Shaw et al. 1995, Whaley et al. 1997, 2000, Eberhardt et al. 1999), and the precise stage (oocyte, embryo or both) during which retinoids exerted their effects was not determined. Our results involving oocytes isolated by OPU following $\mathrm{ROH}$ treatment and subsequently cultured in vitro demonstrate that $\mathrm{ROH}$ can influence development by acting on the oocyte during its intrafollicular growth. In the future, it would be interesting to find out the outcome had the oocyte following $\mathrm{ROH}$ treatment been fertilized in vivo and the embryo recovered at specific stages during pre-implantation development, as done in earlier studies (Shaw et al. 1995, Besenfelder et al. 1996, Whaley et al. 1997, 2000, Eberhardt et al. 1999). 
It is interesting to note that in the present study, the development of embryos following transfer was negatively influenced by $\mathrm{ROH}$ treatment of the oocyte donor cow while RA treatment of the oocyte during IVM in our earlier studies promoted oocyte developmental competence. The animal cell contains all the components required to bind and regulate the release of retinoids, from $\beta$-carotene up to the nuclear effector RA. It is possible that this system could have failed since repeated $\mathrm{ROH}$ administration did not produce long-term increases in blood $\mathrm{ROH}$ concentrations above physiological levels. Instead, excess $\mathrm{ROH}$ could have been compartmentalized and stored (i.e. the follicle). Serum-derived follicular $\mathrm{ROH}$ can bind to specific protein in granulosa cells (Brown et al. 2003) and the oocyte (Mohan et al. 2001). After entry into the cell, $\mathrm{ROH}$ can be metabolized to RA, which can then be bound by specific CRABPs. As previously demonstrated in rats (Bucco et al. 1995, Wardlaw et al. 1997, Zheng et al. 1999), intracellular proteins that regulate RA availability may not be expressed in immature follicles; as a result the availability of RA in the follicle could have gone unchecked. On the contrary, under in vitro conditions, by providing a carefully calculated dose, it is possible to ensure that an optimum concentration of RA is made available to the COCs during in vitro culture.

The present study confirms the existence of an effect of $\mathrm{ROH}$ on the bovine oocyte during intrafollicular growth. As a single dose, injected $\mathrm{ROH}$ increases $\mathrm{ROH}$ concentration in blood by $24 \mathrm{~h}$. By 4 days after injection, blood $\mathrm{ROH}$ clearance was observed, but interestingly $\mathrm{ROH}$ remained higher within the follicle. Weekly repeated $\mathrm{ROH}$ injections enabled the recovery of higher numbers of low-quality oocytes by OPU throughout the cycles studied. Furthermore, total oocytes recovered as well as morulae and blastocyst formation rates increased during the first five sessions in cows treated with $\mathrm{ROH}$. However, $\mathrm{ROH}$ levels measured during OPU cycles did not change, suggesting the non-existence of $\mathrm{ROH}$ downregulation. On the other hand, as previously demonstrated using oocytes from slaughterhouse ovaries, RA stimulated blastocyst development (Duque et al. 2002, Hidalgo et al. 2003). Accordingly, under the RA influence, higher proportions of embryos overcame the developmental block on Day 3 of culture. Once transferred to recipients, blastocysts derived from oocytes from cows treated with $\mathrm{ROH}$ were unable to set pregnancy, showing an early sign of teratogenic effect of $\mathrm{ROH}$. Exposure to $\mathrm{ROH}$ and RA should be avoided in candidate mothers as early as possible prior to the fertilization time.

\section{Acknowledgements}

We thank José Antonio Cachero and José Santos for excellent animal management, and Dr B Olmedilla for HPLC for retinol analysis. Supported by a grant from the Spanish Ministry of Science and Technology (Project AGL2002-01175), Laboratorios Calier, Barcelona, Spain has declared interest in this project. The authors declare that there is no conflict of interest that would affect the impartiality of this scientific work.

\section{References}

Argov N, Arav A \& Sklan D 2004 Number of oocytes obtained from cows by OPU in early, but no late lactation increased with plasma insulin and estradiol concentrations and expression of mRNA of the FSH receptor in granulosa cells. Theriogenology 61 947-962.

Besenfelder UL, Solti J, Seregi M, Müller M \& Brem G 1996 Different roles for $\beta$-carotene and vitamin $A$ in the reproduction of rabbits. Theriogenology 45 1583-1591.

Blondin P, Bousquet D, Twagiramungu $H$, Barnes F \& Sirard MA 2002 Manipulation of follicular development to produce developmentally competent bovine oocytes. Biology of Reproduction $6638-43$.

Bousquet D, Twagiramungu H, Morin N, Brisson C, Carboneau G \& Durocher J 1999 In vitro embryo production in the cow: an effective alternative to the conventional embryo production approach. Theriogenology 51 59-70.

Brief S \& Chew BP 1983 Effects of vitamin A and $\beta$-carotene on reproductive performance in gilts. Journal of Animal Science $\mathbf{6 0}$ 998-1004.

Brown JA, Eberhardt DM, Schrick FN, Roberts MP \& Godkin JD 2003 Expression of retinol-binding protein and cellular retinolbinding protein in the bovine ovary. Molecular Reproduction and Development 64 261-269.

Bucco RA, Melner MH, Gordon DS, Leers-Sucheta S \& Ong DE 1995 Inducible expression of cellular retinoic acid-binding protein II in rat ovary: gonadotropin regulation during luteal development. Endocrinology 136 2730-2740.

Bugavandoss P \& Midgley AR 1988 Biphasic action of retinoids on gonadotropin receptor induction in rat granulosa cells in vitro. Life Sciences 43 1607-1614.

Calder MD, Caveney AN, Smith LC \& Watson AJ 2003 Responsiveness of bovine cumulus-oocyte-complexes (COC) to porcine and recombinant human $\mathrm{FSH}$, and the effect of COC quality on gonadotropin receptor and $\mathrm{Cx} 43$ marker gene mRNAs during maturation in vitro. Reproductive Biology and Endocrinology 114.

Chambon P 1996 A decade of molecular biology of retinoic acid receptors. FASEB Journal 10 940-954.

Chew BP, Holpuch DM \& O'Fallon JV 1984 Vitamin A and beta-carotene in bovine and porcine plasma, liver, corpora lutea, and follicular fluid. Journal of Dairy Science 67 1316-1322.

Coffey MT \& Britt JH 1993 Enhancement of sow reproductive performance by $\beta$-carotene or vitamin A. Journal of Animal Science 71 1198-1202.

Duque P, Díez C, Royo L, Lorenzo PL, Carneiro G, Hidalgo CO et al. 2002 Enhancement of developmental capacity of meiotically inhibited bovine oocytes by retinoic acid. Human Reproduction 17 2706-2714.

Eberhardt DM, Will WA \& Godkin JD 1999 Retinol administration to superovulated ewes improves in vitro embryonic viability. Biology of Reproduction 60 1483-1487.

Faber DC, Molina JA, Ohlrichs CL, Vander Zwaag DF \& Ferré LB 2003 Commercialization of animal biotechnology. Theriogenology 59 125-138.

Frye TM, Williams SN \& Graham TW 1991 Vitamin deficiencies in cattle. Veterinary Clinics of North America. Food Animal Practice $7217-275$.

Gómez E, Royo LJ, Duque P, Carneiro G, Hidalgo C, Goyache F et al. 2003 9-cis-retinoic acid during in vitro maturation improves development of the bovine oocyte and increases midkine but not IGF-I expression in cumulus-granulosa cells. Molecular Reproduction and Development 66 247-255. 
Gómez E, Rodriguez A, Goyache F, Diez C, Jose Royo L, Moreira PN et al. 2004 Retinoid-dependent mRNA expression and poly-(A) contents in bovine oocytes meiotically arrested and/or matured in vitro. Molecular Reproduction and Development 69 101-108.

Goodhand KL, Watt RG, Staines ME, Hutchinson JSM \& Broadbent PJ 1999 In vivo oocyte recovery and in vitro embryo production from bovine donors aspirated at different frequencies or following FSH treatment. Theriogenology 51 951-961.

Graves-Hoagland RL, Hoagland TA \& Woody CO 1988 Effect of $\beta$-carotene and vitamin $A$ on progesterone production by bovine luteal cells. Journal of Dairy Science 71 1058-1062.

Griffith M \& Zile MH 2000 Retinoic acid, midkine and defects of secondary neurulation. Teratology 62 123-133.

Haliloglu S, Baspinar N, Serpek B, Erdem H \& Bulut Z 2002 Vitamin A and beta-carotene levels in plasma, corpus luteum and follicular fluid of cyclic and pregnant cattle. Reproduction in Domestic Animals 37 96-99.

Hattori M, Takesue K, Nishida N, Kato Y \& Fujihara N 2000 Inhibitory effect of retinoic acid on the development of immature porcine granulosa cells to mature cells. Journal of Molecular Endocrinology 25 53-61.

Hidalgo CO, Díez C, Duque P, Facal N \& Gómez E 2003 Pregnancies and improved early embryonic development in bovine oocytes matured in vitro with 9-cis-retinoic acid. Reproduction 125 409-416.

Holm P, Booth PJ, Schmidt MH, Greve T \& Callesen H 1999 High bovine blastocyst development in a static in vitro production system using SOFaa medium supplemented with sodium citrate and myo-inositol with or without serum proteins. Theriogenology $52683-700$.

Huang FJ, Wu TC \& Tsai MY 2001 Effect of retinoic acid on implantation and post-implantation development of mouse embryos in vitro. Human Reproduction 16 2171-2176.

Huang FJ, Shen CC, Chang SY, Wu TC \& Hsuuw YD 2003 Retinoic acid decreases the viability of mouse blastocysts in vitro. Human Reproduction 18 130-136.

Hubbert WT 1974 Factors affecting survival of the bovine fetus and neonate. Theriogenology 1 15-34.

Ikeda S, Ichihara-Tanaka K, Azuma T, Muramatsu T \& Yamada M 2000a Effects of midkine during in vitro maturation of bovine oocytes on subsequent developmental competence. Biology of Reproduction 63 1067-1074.

Ikeda S, Nishikimi A, Ichihara-Tanaka K, Muramatsu T \& Yamada M $2000 \mathrm{~b}$ cDNA cloning of bovine midkine and production of the recombinant protein, which affects in vitro maturation of bovine oocytes. Molecular Reproduction and Development $\mathbf{5 7}$ 99-107.

Izadyar F, Van Tol HT, Colenbrander B \& Bevers MM 1997 Stimulatory effect of growth hormone on in vitro maturation of bovine oocytes is exerted through cumulus cells and not mediated by IGF-I. Molecular Reproduction and Development 47 175-180.

Kaidi S, Bernard S, Lambert P, Massip A, Dessy F \& Donnay I 2001 Effect of conventional controlled-rate freezing and vitrification on morphology and metabolism of bovine blastocysts produced in vitro. Biology of Reproduction 65 1127-1134.

Katamoto H, Yamada Y, Nishizaki S \& Hashimoto T 2003 Seasonal changes in serum vitamin $\mathrm{A}$, vitamin $\mathrm{E}$ and beta-carotene concentrations in Japanese Black breeding cattle in Hyogo prefecture. Journal of Veterinary Medical Science 65 1001-1002.

Kolle S, Sinowatz F, Boie G \& Lincoln D 1998 Developmental changes in the expression of the growth hormone receptor messenger ribonucleic acid and protein in the bovine ovary. Biology of Reproduction 59 836-842.

Kolle S, Stojkovic M, Boie G, Wolf E \& Sinowatz F 2003 Growth hormone-related effects on apoptosis, mitosis, and expression of connexin 43 in bovine in vitro maturation cumulus-oocyte complexes. Biology of Reproduction 68 1584-1589.

Lawrence JL, Payton RR, Godkin JD, Saxton AM, Schrick FN \& Edwards JL 2004 Retinol improves development of bovine oocytes compromised by heat stress during maturation. Journal of Dairy Science 87 2449-2454.

Mangelsdorf DJ, Umesono K \& Evans RM 1994 Cellular biology and biochemistry of the retinoids. In The Retinoids - Biology, Chemistry and Medicine, pp 319-349. Eds MB Sporn, AB Roberts \& DS Goodman. New York: Raven Press.

Marill J, Idres N, Capron CC, Nguyen E \& Chabot GG 2003 Retinoic acid metabolism and mechanism of action: a review. Current Drug Metabolism 4 1-10.

Merton JS, de Roos APW, Mullaart E, de Ruigh L, Kaal L, Vos PLAM et al. 2003 Factors affecting oocyte quality and quantity in commercial application of embryo technologies in the cattle breeding industry. Theriogenology 59 651-674.

Minegishi T, Karino S, Tano M, Ibuki Y \& Miyamoto K 1996 Regulation of midkine messenger ribonucleic acid levels in cultured rat granulosa cells. Biochemical and Biophysical Research Communications 229 799-805.

Minegishi T, Hirakawa T, Kishi H, Abe K, Tano M, Abe Y et al. 2000 The mechanisms of retinoic acid-induced regulation on the follicle-stimulating hormone receptor in rat granulosa cells. Biochimica et Biophysica Acta 1495 203-211.

Mohan M, Malayer JR, Geisert RD \& Morgan GL 2001 Expression of retinol-binding protein messenger RNA and retinoic acid receptors in preattachment bovine embryos. Molecular Reproduction and Development 60 289-296.

Mohan M, Malayer JR, Geisert RD \& Morgan GL 2002 Expression patterns of retinoid $\mathrm{X}$ receptors, retinaldehyde dehydrogenase, and peroxisome proliferator activated receptor gamma in bovine preattachment embryos. Reproductive Biology and Endocrinology $66692-700$.

Mohan M, Thirumalapura NR \& Malayer J 2003 Bovine cumulusgranulosa cells contain biologically active retinoid receptors that can respond to retinoic acid. Reproductive Biology and Endocrinology 1104.

Morris-Kay GM \& Ward SJ 1999 Retinoids and embryonic development. International Review of Cytology 188 73-133.

Niederreither K, Subbarayan V, Dolle P \& Chambon P 1999 Embryonic retinoic acid synthesis is essential for early mouse post-implantation development. Nature Genetics 21 346-347.

Ohlsson C, Lovstedt K, Holmes PV, Nilsson A, Carlsson L \& Tornell J 1993 Embryonic stem cells express growth hormone receptors: regulation by retinoic acid. Endocrinology 133 2897-2903.

Olmedilla B, Granado F, Blanco I \& Rojas E 1992 Determination of nine carotenoids, retinol, retinyl palmitate and alpha-tocopherol in control human serum, using two internal standards. Food Chemistry 45 205-213.

Parrish J,, Susko-Parrish JL, Leibfried-Ruthledge ML, Critser ES, Eyestone WH \& First NL 1986 Bovine in vitro fertilization with frozen-thawed semen. Theriogenology 25 591-600.

Petyim S, Bage R, Hallap T, Bergqvist AS, Rodriguez-Martinez H \& Larsson B 2003 Two different schemes of twice-weekly ovum pickup in dairy heifers: effect on oocyte recovery and ovarian function. Theriogenology 60 175-188.

Pieterse MC, Vos PLAM, Kruip Th AM, Wurth YA, Van Beneden Th H, Willamse AH et al. 1991 Transvaginal ultrasound guided follicular aspiration of bovine oocytes. Theriogenology 35 19-24.

Rutledge JC 1997 Developmental toxicity induced during early stages of mammalian embryogenesis. Mutation Research 396 $113-127$

Schweigert FJ \& Siegling C 2001 Immunolocalization of retinol-binding protein, cellular retinoic acid-binding protein $\mathrm{I}$ and retinoid $\mathrm{X}$ receptor beta in the porcine reproductive tract during the oestrous cycle. Reproduction, Fertility, and Development 13 421-426.

Schweigert FJ \& Zucker H 1988 Concentrations of vitamin A, beta-carotene and vitamin $\mathrm{E}$ in individual bovine follicles of different quality. Journal of Reproduction and Fertility $\mathbf{8 2}$ 575-579.

Schweigert FJ, Lutterbach A, Rambeck WA \& Zucker H 1986 Vitamin A- and beta-carotene concentrations in bovine follicular 
fluid in relationship to follicle size. Journal of Veterinary Medicine A, Physiology, Pathology, Clinical Medicine 33 360-364.

Shaw DW, Farin PW, Washburn SP \& Britt JH 1995 Effect of retinol palmitate on ovulation rate and embryo quality in superovulated cattle. Theriogenology 44 51-58.

Sirard MA, Picard L, Dery M, Coenen K \& Blondin P 1999 The time interval between $\mathrm{FSH}$ administration and ovarian aspiration influences the development of cattle oocytes. Theriogenology $\mathbf{5 1}$ 699-708.

Slootweg MC, Salles JP, Ohlsson C, de Vries CP, Engelbregt MJ \& Netelenbos JC 1996 Growth hormone binds to a single high affinity receptor site on mouse osteoblasts: modulation by retinoic acid and cell differentiation. Journal of Endocrinology $\mathbf{1 5 0}$ 465-472.

Velasquez-Pereira J, McDowell LR, Risco CA, Prichard D, Martin FG, Calhoun MC et al. 1998 Effects on performance, tissue integrity, and metabolism of vitamin E supplementation for beef heifers fed a diet that contains gossypol. Journal of Animal Science $\mathbf{7 6}$ $2871-2884$.

Wardlaw SA, Bucco RA, Zheng WL \& Ong DE 1997 Variable expression of cellular retinol- and cellular retinoic acid-binding proteins in the rat uterus and ovary during the estrous cycle. Biology of Reproduction 56 125-132.
Whaley SI, Hedgpeth VS \& Britt JH 1997 Evidence that injection of vitamin A before mating may improve embryo survival in gilts fed normal or high-energy diets. Journal of Animal Science $\mathbf{7 5}$ 1071-1077.

Whaley SL, Hedgpeth VS, Farin CE, Martus NS, Jayes FC \& Britt JH 2000 Influence of vitamin A injection before mating on oocyte development, follicular hormones, and ovulation in gilts fed high-energy diets. Journal of Animal Science $\mathbf{7 8}$ 1598-1607.

Zheng WL, Bucco RA, Sierra-Rievera E, Osteen KG, Melner MH \& Ong DE 1999 Synthesis of retinoic acid by rat ovarian cells that express cellular retinoic acid-binding protein-II. Biology of Reproduction $60110-114$.

Zile MH 2001 Function of vitamin A in vertebrate embryonic development. Journal of Nutrition 131 705-708.

Received 27 October 2004

First decision 26 November 2004

Revised manuscript received 10 December 2004

Accepted 17 December 2004 